\title{
Medical futility and the social context
}

\author{
Robert Halliday Utica College of Syracuse University, New York, USA
}

\begin{abstract}
The concept of medical futility has come to be seen in some quarters as a value-neutral trump card when dealing with issues of power and conflicting values in medicine. I argue that this concept is potentially useful, but only in a social context that provides a normative framework for its use. This social context needs to include a broad consensus about the purpose of medicine and the nature of the physician-patient relationship.
\end{abstract}

\section{Introduction}

Legend has it that the daughters of Danaus, king of Argos, killed their husbands on their wedding night and were condemned to fetch water in leaky sieves, an action that was doomed to failure by its very nature. From the Latin word for leaky (futilis) we get "futile" and, like the aquatic labours of Danaus's daughters, many medical procedures are held to be futile and pointless. Such procedures include inhospital cardiopulmonary resuscitation (CPR) for certain categories of patients, the intubation and ventilation of patients who have been in a persistent vegetative state (PVS) for more than three months, organ transplants for certain categories of patient and the prescription of certain drugs or procedures inappropriate to the condition of the patient, such as antibiotics for a common cold. The techniques and procedures are held to be futile because they cannot achieve what they are ostensibly trying to accomplish.

The debate over futility in medical treatment has a relatively short history in its current incarnation, although the issue is as least as old as the writings of Hippocrates who said that there is "a time when we should stop treating". Plato expressed similar ideas when he said that a responsible physician would not pander to those who should not be treated "even though they be rich as Midas". The current intensity of debate can be traced to a 1983 article by Bedell and Delbanco ${ }^{1}$ in which they showed the ineffectiveness of CPR on patients with metastatic disease, acute strokes, sepsis, renal failure, pneumonia and

\section{Key words}

Medical futility; ethics. on those whose resuscitation took more than thirty minutes. Other studies have demonstrated CPR's lack of success (defined as "survival to discharge") for elderly patients ${ }^{2}$ and very low birth-weight babies. ${ }^{3}$ Since 1990 there has been an explosion of articles on the subject of medical futility, its definition and implications. Two journals of medical ethics have devoted most of an issue to the subject. ${ }^{4}$ Reflecting its source, the debate has tended to focus on modern methods of intervention, particularly CPR, and maintaining PVS patients on life support, although it has recently begun to include other issues.

I begin this paper by looking at the situation of conflict that has made the concept of futility so attractive as a possible resolution. I then examine the definitions of futility that have been offered in the course of the debate and argue that simply refining definitions is not enough. Futility is a concept that is inextricably bound up with a social understanding of the nature and purpose of the practice of medicine and the nature of the relationship between patient and health care provider. The futility debate is both a symptom of the need for a fundamental discussion of these issues and a possible focal point for that discussion.

\section{Part 1 - conflict and control}

The attempt to define futility is not simply an exercise in abstract argument, but is part of a threeway struggle for control within and around the practice of medicine. The past decades have seen an increasing suspicion of physicians who are perceived to be imposing their own value judgments in the guise of science, "playing God", as it is often described. This change is reflected in both the professional and popular literature. ${ }^{5}$

Such a view is not without statistical support. For instance, a nationwide survey of 879 physicians practising in adult intensive care units in the United States revealed that $96 \%$ of them had "withheld and withdrawn life-sustaining medical treatment on the expectation of a patient's death, and most do so frequently in the course of a year". Many physicians $(34 \%)$ continue life-sustaining treatment "despite? 
patient or surrogate wishes that it be discontinued" and many unilaterally withhold $(83 \%)$ or withdraw $(82 \%)$ life-sustaining treatment that they judge to be futile. Some of these decisions are made "without the knowledge or consent of patients or their surrogates, and some are made over their objections". ${ }^{6}$

Physicians, on the other hand, feel that the strong desire on the part of patients to make autonomous decisions has taken more control out of their hands, often with detrimental effects to both parties. John Paris and Frank Reardon have argued that in the trend towards giving increased decision-making authority to patients, the physician has been reduced from a "moral agent - one with professional responsibilities and limits on what may legitimately be done - and transformed into an extension of the patient's (or family's) whim, fantasy, or unrealisable hopes and desires". This, in turn, means that physicians could become unwilling "partners in harmful, selfmutilating, and even self-destructive patient actions". ${ }^{7}$ The third party to this struggle for control are the insurance companies and Health Maintenance Organisations (HMO) in the United States, and national health care institutions, such as the National Health Service (NHS) in Britain, who are trying to control costs and determine coverage.

All sides hope that delineating a concept of futility would return a portion of the lost control. Enthusiastic proponents of physiologic futility, called "futilitarians" by Arthur Caplan, ${ }^{8}$ continue to trumpet the usefulness of futility as a way of determining the point at which physicians may, and should, refuse to provide a certain treatment. Schneiderman et al, for instance, assert that patient choice in the matter of accepting or declining treatment should be restricted to non-futile procedures only. A determination that a treatment is futile would act as a threshold which "frees the physician from the obligation to provide medical treatment". 9 By implication, it would also free a state or HMO from the obligation to pay for it.

\section{Part 2 - definitions}

Early in the current round of debate, a range of possible definitions for futile procedures was offered including: "failing to prolong life", 10 "failing to achieve the patient's wishes", 11 "failing to achieve a physiologic effect on the body", ${ }^{12}$ and "failing to achieve a therapeutic benefit for the patient". ${ }^{13}$ Each definition was too fraught with attendant difficulties. Then, in 1990, Lawrence Schneiderman, Nancy Jecker and Albert Jonsen, in an article that has become something of a benchmark for futility discussions, defined a futile action as one "that cannot achieve the goals of the action, no matter how often repeated". ${ }^{9}$ In more precise terms they described futility as "an expectation of success that is either predictably or empirically so unlikely that its exact probability is often incalculable" and suggested that "when physicians conclude (either through personal experience, experiences shared with colleagues, or considerations of published empirical data) that in the last 100 cases a medical treatment has been useless, they should regard that treatment as futile". ${ }^{14}$ This, they argue, is a purely quantitative account based on the probability that a treatment will have the desired effect, a probability established by the empirical methods of medicine as a science. When $p<0.01$ a treatment is futile.

They also argue that, along with its quantitative aspect, futility has a qualitative aspect. A futile treatment is also one that "merely preserves permanent unconsciousness or that fails to end total dependence on intensive medical care". They further suggest that "physicians should distinguish between an effect, which is limited to some part of the patient's body, and a benefit which the patient has the capacity to appreciate and which improves the patient as a whole". Treatment which fails to provide a benefit, even when it produces an effect, should be deemed "futile". ${ }^{9}$ The distinction between a quantitative and qualitative aspect to futility, between effect and benefit, has been echoed and endorsed by others. ${ }^{15}$

Because the issue of control within the physicianpatient relationship is often understood in terms of competing or clashing values, there is a strong urge to find a value-free definition of futility. Few writers have argued that qualitative futility could be regarded as value-neutral, the issues of patient perception of benefit are too complex and subjective. Instead the debate has focused on quantitative or physiologic futility and the determination of whether or not a specific treatment has a particular quantifiable, physiologic effect. This, it is argued, is the type of futility that can approach, and achieve, value neutrality. ${ }^{16}$ I do not intend to discuss qualitative definitions of futility in this paper but instead to focus on quantitative definitions of futility. Because quantitative definitions rely on data gathered from physiologic effects, I will use both terms to discuss this type of definition.

It is tempting to see physiologic futility, the determination that, for a specific treatment, there is a less than $1 \%$ chance that it will have the desired effect on a particular patient's condition, as a purely factual determination, and I think a strong case can be made that it is just that. However, that said, I see several serious problems with this concept. These problems do not themselves render the concept vacuous, but its limitations need to be recognised.

\section{Part 3 - problems with physiologic futility}

The first problem is the arbitrariness of the standard. Schneiderman et al suggested the $\mathrm{p}<0.01$ standard because some standard was necessary and that seemed as good as any. However, very few physicians are in a position clearly to recall the last 100 
uses of a therapy let alone correct for variables in those 100 uses. Secondly, very few journal articles describe failures in treatment and so collecting accurate data about failure rates of drugs or procedures is very difficult. Thirdly, it seems to me that in many instances the arbitrary 100 instances is simply too high. If I go to a physician seeking treatment and am told that the drug he/she hinking of prescribing has had no therapeutic effect on the last 20 patients with my condition, I may legitimately wonder why he/she is prescribing it for me.

\section{Normative standard}

The more fundamental problem, however, lies in the idea that the concept of physiologic futility can be both purely factual and, by itself, useful. In practice, the nearer a determination of futility comes to being purely factual, the further it gets from fulfilling the task its proponents set for it, that is in providing a normative standard by which to judge the appropriateness of a course of treatment. There is a big distinction between the determination that a particular treatment will not have the intended physiologic effect (for example CPR will not restore the heart's autonomous functioning, or a course of antibiotics will not cure a pneumonia) and the decision that, because of this futility, the treatment should not be used. This gap between "is" and "ought" yawns wider the closer one gets to a purely factual determination of futility.

In ignoring this chasm between the descriptive and the prescriptive, those who use a physiological definition of futility as a normative trump card effectively smuggle in a number of questionable assumptions. The first of these is that factual determinations of this sort are the most appropriate measures in this situation, that this is how medicine ought to be done. However, as Schneiderman and Jecker, together with Kathy Faber-Langendoen ${ }^{17}$ argue, the strictly physiologic determination of futility represents "a reductionist approach that is incompatible with medicine, placing primary value on organ function and body substance. It illustrates how far medicine has strayed into the realm of biologic fragmentation. To specify narrow physiologic objectives as the goals of medical practice is not 'value neutral,' but is a value choice that is about as far from the patient-centred tradition of the medical profession as it is possible to be."

A second, and related, assumption is that only causally produced effects and their directly related benefits count. However, there may be other, noncausal, reasons making the treatment worth performing. How important, for instance, is any indirect psychological benefit that may be derived by patients from the very fact that they are being cared for? When patients are scared of being left alone, and when that fear affects their health, doing anything, even something "futile", may be better medicine than doing nothing.
The inclusion of possible psychological benefits $\frac{\text { T⿱宀 }}{5}$ in a determination of the worth of a course of $\bar{\delta}$. treatment, however, raises further problems of its own. What happens when patients make irrational $\stackrel{5}{\rightarrow}$ requests but feel better for having them granted? What happens when a patient experiences something $\overline{\bar{\sigma}}$. as a benefit that seems to the medical staff involved in $\frac{\bar{s}}{-}$ treatment to be a less desirable state? How is a physi- $\stackrel{\oplus}{\complement}$

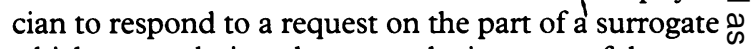
which seems designed to serve the interests of the sur- $\overrightarrow{0}$

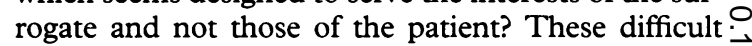
questions arise the moment one includes indirect psy- $\vec{\omega}$ chological benefit in the evaluation of a course of $\stackrel{S}{S}$ treatment. Not to do so, however, is itself a value $\overline{\mathbb{D}}$ judgment that needs to be defended.

A third assumption is that only the benefits experienced by the patient count. Erich Loewy and $\omega$ Richard Carlson point out that not all benefits of a $\vec{\infty}$ treatment are experienced by the patient. ${ }^{18}$ They argue that such side-benefits are a legitimate compo- nent of an evaluation of futility.

"To continue treatment that causes the patient no suffering but that prolongs life for a reasonable $\vec{\bullet}$ length of time while those concerned with the $\Theta$ patient come to terms with the situation should not * be morally offensive. . . . A given course of action may be futile for the patient himself/herself, but may have distinct value for the family, the community, or the medical team, and, therefore, not be futile in that sense."18

While I find the idea of keeping a patient techni- $\overrightarrow{\bar{O}}$ cally alive in order for the medical team or family to 3 come to terms with their impending death somewhat repulsive, the question of whose benefit should? count in determinations of futility is a legitimate one.

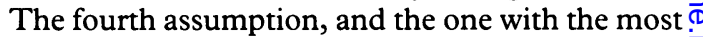
troubling implications, is that futile treatments should be suspended.

\section{Negative right}

In the United States, the Patient Self Determination $\frac{7}{0}$ Act guarantees patients considerable control over their course of treatment. These powers of control $N^{N}$ are based on a negative right, the right to freedom $N$ from interference, and primarily permit patients to N decline any treatment, even life-saving treatment. $\omega$ Decisions to refuse treatment are sometimes made on religious grounds (for example, Jehovah's Witnesses refusing blood transfusions) and similar provisions in other countries recognise the impor- tance of deeply held religious convictions in making ${ }^{\circ}$ decisions about one's own health care options. However, if this exercise of religion is to be taken $\frac{?}{\mathbb{Q}}$ seriously, then there has to be some recognition of $\stackrel{\varrho}{\sigma}$ deeply held principles that require, rather than refuse, treatment.

This is brought vividly to the fore in cases such as? Baby $\mathrm{K}$ who was born anencephalic and quicklyô. needed a ventilator. The hospital sought the court's? 
permission to refrain from ventilation on the grounds that such a treatment was futile. The mother, Mrs $\mathrm{H}$, vehemently demanded all possible treatment because, as a fundamentalist Christian, she believed that all human life had a sacred and absolute value. She held to what Helga Kuhse calls the SLP, or sanctity of life principle. ${ }^{19}$ For her the boundaries of what was technically possible and would keep her baby alive defined what was appropriate, while the hospital believed that the boundaries of what was appropriate lay well within what was possible. $^{20}$

It is often said that the two cases are not analogous for there is no positive right involved, no right to be supplied with something. The right to say no to a treatment option is not the same as the right to demand it. While there is no doubt that there is a difference between the two kinds of claims, the idea that the religious values behind the negative claim cannot equally support a positive claim is less clear. As long as beliefs such as SLP exist, to ignore those beliefs is to operate in one value climate to the exclusion of another and is not a value-neutral decision. As Kathleen Boozang points out, if the courts or a social consensus move towards giving physicians the power to override fundamental religious beliefs on the basis of a secular determination of futility, that would be an unprecedented denial of the importance to an individual of his or her religious beliefs. ${ }^{21}$

\section{Religious principles}

Ultimately I believe that there is a strong case to be made that religious principles convey a negative but not a positive force, but this position has yet to become part of our social consensus. In the absence of such a consensus, the tension between these two normative schemes can be extreme. Those who accept the sanctity of life principle can feel abandoned by the medical establishment, while the medical establishment in turn can feel that they are being pressured to provide services to which they have moral objections. ${ }^{22}$

The issue of futility is of central importance in today's health care climate and, given the perception of the power struggle between patients and physicians as a battle over values, it would seem that a valueneutral definition of futility is essential. However, it is increasingly clear that a value-neutral definition of physiologic futility which, by itself, resolves these conflicts, is not possible. While it is possible to create a value-neutral definition, its effective use requires a context of value-laden decisions and positions, a normative social context. These decisions and positions include: (1) that setting the value of futility at $p>0.01$ is appropriate, (2) that the reductionist approach to health exemplified in the physiologic determination of futility is appropriate, (3) that uncaused psychological benefits to patients and others are irrelevant side issues in the determination of a treatment's futility and, most central of all, (4) that futile treatments should be suspended, or not initiated, regardless of the desire on the part of the patient or surrogate.

\section{Part 4 - the social context}

If the effective use of a value-neutral definition of physiologic futility requires a normative social context it is important to understand the two main components of that context: an understanding of an appropriate physician-patient relationship and an understanding of the nature and purpose of medicine. I have discussed above the changing perception of the nature of the physician-patient relationship. Clearly all parties to this change need to be part of a public discussion on the current nature of this relationship and the changes that need to be made.

A similar public discussion needs to take place concerning the nature and purpose of medicine itself. Here a similarly profound change seems to have taken place in the past decades; we have come to assume that the purpose of medicine is to effect a recovery and that whenever a recovery does not take place some failure has occurred. Although physicians have known since Hippocrates that curing is not always possible some medical professionals and many members of the public seem to have forgotten this fact. The source of this amnesia seems to me to be threefold:

Firstly, as modern technology produces some spectacular defeats of previously impregnable diseases we have grown to rely on it as the cure for all ills and to have a technological "fix-it" attitude to our own bodies. We feel that we have not "done everything possible" unless whatever is wrong gets fixed. Death becomes a sign of failure instead of an inevitable end to all biological life. ${ }^{23}$ Secondly, in cases where treatment decisions are being taken by families or health care proxies, there is a desire to "do everything possible" for someone about whom we care. Coupled with the reliance on technology discussed above, this becomes a desire to have every remotely applicable technology applied: we feel compelled to the heroic and quixotic, rather than the appropriate. The application of technology becomes one of the more powerful ways in which we can express our love for the patient. Thirdly, in America particularly, although by no means confined to it, there are religious considerations that lead some patients, relatives, and medical professionals to feel obligated to try all possible avenues or to maintain apparently hopeless treatments in the expectation of a miracle. This emphasis on curing and fixing what is wrong is not confined to patients. Time and again reflective physicians remind their colleagues that a patient for whom further treatments are futile is not someone who is no longer worthy of medical attention. These reminders would not be necessary were the tendency to regard these patients as beyond the purview of medical care not present. 


\section{Conclusion}

The debate about futility has been surprisingly heated and shows no signs of letting up. This reflects what is at stake for all parties, control of the medical environment. However, a purely physiologic definition of futility is not going to provide the value-neutral point of control, the "factual trump card" that many seek. To be useful, a physiologic definition of futility must be used within a normative social context that outlines an acceptable account of the patient physician-relationship and an understanding of the purpose of medicine. This does not mean that such a definition is useless, but it is up to those of us engaged in this debate at whatever level to recognise the need for this context and to work to provide it.

\section{Robert Halliday is Associate Professor, Utica College,} Utica NY, USA.

\section{References and notes}

1 Bedell S, Delbanco T, Cook E, et al. Survival after cardiopulmonary resuscitation in the hospital. New England Fournal of Medicine 1983; 309: 569-76.

2 Murphy D. Do-not-resuscitate orders: time for reappraisal in long-term care institutions. Fournal of the American Medical Association 1989; 260: 2098-2101.

3 Lantos J, Miles S, Silverstein M, et al. Survival after cardiopulmonary resuscitation in very low birth-weight babies: is CPR futile therapy? New England fournal of Medicine 1988; 318: 91-5.

4 Cambridge Quarterly of Healthcare Ethics 1993; 2, and The fournal of Law, Medicine $\mathcal{E}$ Ethics 1992; 20.

5 For a summary of professional literature on this subject see Schneiderman L, Jecker S, Jonsen A. Medical futility: response to critiques. Annals of Internal Medicine 1996; 125: 669-74. Popular literature illustrates an interesting evolution. In Medicine and the management of living, Chicago: University of Chicago Press, 1984, William Arney and Bernard Bergen argue that since the 1950 s medicine has become more patientoriented, not because of a patient rebellion, but because medicine itself became interested in patients' subjective experiences. The medical establishment for Arney and Bergen is competent and benevolent, and interested in you. This contrasts with the 1985 book by David Nash, MD, Medical mayhem, New York: Walker and Company, in which he exposed flaws in the medical system that resulted in unnecessary treatments and procedures. He urged patients to take responsibility for their own health care, to become informed and to question their physicians' decisions. A similar set of charges and recommendations was made in Lawrence Horowitz's 1985 book, Taking charge of your medical fate, New York: Random House, this time with an endorsement by Senator Edward Kennedy on the cover. In 1994 Leslie Laurence and Beth Weinhouse chronicled the sexism in the medical establishment in their book, Outrageous practices: the alarming truth about how medicine mistreats women, New York: Fawcett Columbine. They seek to find ways to change the entire medical establishment and to "empower all patients men, women, and children": 353 . Hilary Rodham Clinton provides the foreword to a 1995 book edited by
Marc S Miller, Health care choices for today's consumer, $\underset{+}{\stackrel{m}{ \pm}}$ Washington DC: Living Planet Press. The goal of the $\overline{\bar{C}}$ book is to enable "increasing numbers of consumers to": become more confident and effective decision-makers in the health-care marketplace": ix, and it includes ano entire chapter on consumer rights, including the rights $\frac{\sigma}{\sigma}$ to refuse or demand certain treatments. Jeffrey $\overline{\bar{c}}$. Thurston takes a different tack in his 1996 book, Death $\underset{\mathbb{\mathbb { }}}{\overparen{\nabla}}$ of compassion: the endangered doctor-patient relationship, Texas: WRS Publishing. Thurston argues that HMOses and other managed care plans are coming between physicians and patients, controlling the options physi-.? cians have and depriving patients of their full range of $\vec{\omega}$ options. If the other books see the patient's need too stand up to the medical establishment, this one sees both the patient and physician as allies against an army of faceless bureaucrats.

6 Asch D, Hansen Fletcher J, Lanken P. Decisions to limit or continue life-sustaining treatment by critical $\vec{A}$ care physicians in the United States: conflicts between $\infty$ physicians' practices and patients' wishes. American $\mathrm{O}$ Fournal of Respiratory and Critical Care Medicine 1995; 151: 288-92.

7 Paris J, Reardon F. Physician refusal of requests for futile or ineffective interventions. Cambridge Quarterly of Healthcare Ethics 1992; 2: 127-34. The quotes are from page 128 .

8 Caplan A [editorial]. Annals of Internal Medicine 1996; 125: 688-9.

9 Schneiderman L, Jecker N, Jonsen A. Medical futility: its meaning and ethical implications. Annals of Internal Medicine 1990; 112: 949-54.

10 Brett A, McCullough L. When patients request specific $\stackrel{\mathbb{2}}{\mathrm{Q}}$ interventions: defining the limits of the physician's $\overrightarrow{\bar{O}}$ obligations. New England fournal of Medicine 1986; 315:3 1347-51.

11 Blackhall L. Must we always use CPR? New Englando Fournal of Medicine 1987; 317: 1281-4.

12 Youngner S. Who defines futility? Fournal of the $\overline{\overline{\mathrm{S}}}$ American Medical Association 1988; 260: 2094-5.

13 Murphy D. Do-not-resuscitate orders: time for reappraisal in long-term care institutions. fournal of the American Medical Association 1988; 260: 2098-2101.

14 Schneiderman L, Jecker N. Futility in practice. Archives $\stackrel{\circ}{\supset}$ of Internal Medicine 1993; 153: 437-41.

15 For one influential article that endorses this distinction see Callahan D. Medical futility, medical necessity: the- $\bar{N}$ problem-without-a-name. Hastings Center Report 1991; 21(4): 30-5.

16 See for instance Truog R, Brett A, Frader J. The problem with futility. New England Fournal of Medicine $\sigma$ 1992; 326: 1560-4. They argue that physiologic futility is the determination that a treatment cannot achieve its physiologic objective. They further argue that a physician is not obligated to offer or provide a futile treat-

17 Schneiderman L, Faber-Langendoen K, Jecker $\mathrm{N}$. $\frac{\overrightarrow{0}}{\mathbb{D}}$ Beyond futility to an ethic of care. The American fournalo of Medicine 1994; 96: 110-4.

18 Loewy E, Carlson R. Futility and its wider implica-б tions. Archives of Internal Medicine 1993; 153: 429-31 and 430 .

19 Kuhse $\mathrm{H}$. The sanctity of life doctrine in medicine: a critique. New York: Oxford University Press, 1987.

20 The issue of Mrs H's religious beliefs was lost as the? 
case moved through the courts and the issue was ultimately decided in favour of Mrs $\mathrm{H}$, based on the Americans With Disabilities Act, anencephaly being classed as a disability in this case, and the Emergency Medical Treatment and Active Labor Act. The lower court decision however, which was upheld, also discussed the free exercise of religion.

21 Boozang K. Death wish: resuscitating self determination for the critically ill. Arizona Law Review 1993: 35: 23-85.

22 To date no US court has issued a general ruling on a physician's legal obligation to provide treatment deemed to be futile, but a number of restraining orders have been issued in individual cases compelling physicians and hospitals to continue treatment. See for instance the case of Ryan Nguyen. Case No 94-206074-5, Superior Court, State of Washington, County of Spokane. Jewell M. Judge asked to keep infant on life-support. The Associated Press 1994 Dec 13. Struthers $M$. The medical futility debate continues. Minnesota Medicine 1995; 78: 29-31.

23 For a further discussion of this issue see Bresnahan J. Medical futility or the denial of death. Cambridge Quarterly of Healthcare Ethics 1993; 2: 213-7, and Becker E. The denial of death. New York: Free Press, 1973.

\section{News and notes \\ Call for abstracts}

The 12th annual conference of the European Society for Philosophy of Medicine and Health Care will be held from August 20-22 1998 in Marburg, Germany. Abstracts and registration are called for by November 1 1997.

The theme of the conference is "Philosophy of and Philosophy in Healthcare Education".
For more information please contact: Professor Dr Henk ten Have, secretariat ESPMH, Dept of Ethics, Philosophy and History of Medicine, Faculty of Medical Sciences, Catholic University of Nijmegen, PO Box 9101, $6500 \mathrm{HB}$ Nijmegen, the Netherlands. Fax: 024-3540254 - from abroad: + +31-243540254 . 